\title{
A Study on Total Rewards Management in Philippine Healthcare Companies: An Occupational Issue
}

\author{
${ }^{1}$ University of the Philippines School of Labor and Industrial Relations \\ ${ }^{2}$ University of the Philippines School of Labor and Industrial Relations \\ ${ }^{3}$ National Institutes of Health, University of the Philippines Manila
}

Virgel C. Binghay, $\mathrm{PhD},{ }^{1}$ Sophia Francesca Lu, $\mathrm{MOS}^{2}$ and Jinky Leilanie Lu, MOH, $\mathrm{PhD}^{3}$

\begin{abstract}
Introduction. Companies and hospitals in the healthcare industry, like other businesses, are not exempted from the rising labor costs and growing dissatisfaction among employees. The assessment and optimization of total rewards management (TRM) are important since TRM consists of monetary and non-monetary rewards given to employees in exchange for their time, talents, and efforts.
\end{abstract}

Objective. This study assessed the TRM in Philippine healthcare companies. This study also looked into the organizational structure of various health-service companies and their TRM, and the difference between companies with TRM and without TRM in terms of pay, benefits, work-life balance, career development, and performance recognition.

Method. A total of 74 human resource personnel were randomly sampled from healthcare companies in the Philippines. A survey questionnaire was administered with items on TRM philosophy divided into five parts - pay, benefits, worklife balance, career development, and performance recognition. High mean scores per TRM component correspond to higher levels of agreement to positive statements to the corresponding TRM component. Chi-square test was used to determine the association between various demographic variables and the existence of a TRM philosophy in a company. T-test was used to determine whether the differences in the mean scores per TRM component were statistically significant or not.

Results. Less than half (44\%) of the included companies have TRM and companies in Metro Manila were more likely to have an existing TRM philosophy. Companies in the healthcare sector usually disseminate information on TRM during town hall meetings, and not during onboarding. Employees in the healthcare companies had strict work schedules as most employers did not allow flexi-time arrangements. This may have contributed to burnout and stress that are common in most companies. Lastly, employees working in companies with a TRM philosophy do not experience significantly better pay, benefits, work-life balance, career development, and performance recognition than those working in companies without TRM.

Conclusion. These findings suggest that even companies with an established TRM philosophy need significant improvement in their TRM processes for TRM to translate to better pay, benefits, work-life balance, career development, and performance recognition.

Key Words: total rewards management, healthcare companies, work-life balance, career development, performance, recognition

\section{INTRODUCTION}

Health is a basic human right. Regardless of race, religion, political belief, economic or social condition, every human being must enjoy the highest attainable health standard. ${ }^{1}$ The Philippine constitution recognizes the Filipinos'

Corresponding author: Virgel C. Binghay, PhD School of Labor and Industrial Relations University of the Philippines Diliman

Quezon City 1101, Philippines

Email:vcbinghay@up.edu.ph right to health and makes them aware of health-related matters. However, the health workforce's high attrition rate aggravates the critical shortages in medical professionals while also being a barrier to universal health coverage. ${ }^{2}$ 
One of the key components of attrition is labor migration $^{3}$ that is prevalent in the Philippines. The continually increasing dependence on labor migration, particularly by healthcare workers, has resulted in a more fragile healthcare system. Due to rapid turnover and a permanent loss of skilled and experienced health workers to labor migration, patient outcomes are becoming compromised - with shortages in professionals resulting in high cross-infection rates, increased accident rates, patient injuries, and adverse effects after surgery. ${ }^{2}$

There are 17,000 to 20,000 health professionals that leave the Philippines to work abroad every year. ${ }^{4}$ The widespread desire of health workers to migrate is influenced mainly by the country's situation relative to their respective families. ${ }^{5}$ Globally, the critical reasons for attrition in the healthcare industry include low salaries, lack of access to professional development, lack of adequate supervision, poor working conditions (lack of facilities, medical equipment, and technology), stress, large workloads, and lack of motivation or job satisfaction. ${ }^{2}$ In the Philippines, the most common reasons for migration are the variable wage rates that do not allow health workers to earn decent living wages, poor working conditions, and socio-political factors. ${ }^{6}$ Aside from patient outcomes being compromised, national losses from the high attrition rate of healthcare workers include inadequate funding for the development of health system infrastructure, increased spending of available resources on training staff replacements, and a decrease of educators and trainers in the medical field. ${ }^{6}$ To address the massive impact of high attrition rate caused by both labor migration and high voluntary separation in the professions of Human Health and Social work, ${ }^{7}$ the Philippines has adopted several strategies to harmonize workforce planning in the healthcare industry, focusing on improved recruitment and retention, career planning, and better compensation packages. ${ }^{6}$

Total rewards, defined as monetary and non-monetary rewards given to employees in exchange for their time, talents, and efforts, have five advantages that can arguably help control the high attrition rate in the country's healthcare industry. These advantages include increased flexibility to create different blends of reward packages for different workforce segments, improved recruitment and retention, reduced labor and turnover costs, increased visibility in a tight labor market, and increased profitability for stakeholders. ${ }^{8}$ Previous concepts on employee satisfaction focused heavily on monetary awards and career development, and not the totality of a total rewards system such as the concept being introduced and studied here. ${ }^{5,6}$ Following the premise that total rewards can serve as a solution to the high attrition rate, this study aimed to assess the integration of total rewards philosophy in Philippine health-service industries, and identify strengths and gaps in policies related to total rewards practices.

Companies and hospitals in the healthcare industry, like other businesses, are not exempted from the rising labor costs and growing dissatisfaction in employees. Hence, the assessment and optimization of total rewards can help rein in the organization's labor expenses and impact employee satisfaction and performance.

This study aimed to assess total rewards management (TRM) in Philippine healthcare companies. This study also looked into the various organizational structures of healthservice companies and their TRM, and the difference between companies with TRM and without TRM in terms of pay, benefits, work-life balance, career development, and performance recognition.

\section{METHODS}

We randomly sampled 74 human resource personnel from various healthcare companies in the Philippines. Informed consent was obtained to signify their willingness to participate in the study. Validation was done before the actual survey. A survey questionnaire was administered to gain information into how a TRM philosophy was adopted or applied in the industries in this study, and whether there was a difference between those with TRM and without TRM in terms of occupational benefits. The variables included in the questionnaire were: the type of industry, type of company, business site, years since establishment, number of regular and non-regular employees, the existence of a union of workers, and whether there is an existing total reward management philosophy in the company. The survey also contained items on TRM philosophy divided into five parts: pay, benefits, work-life balance, career development, and performance recognition. Each part had fifteen items, wherein each item tests the respondents' level of agreement to a statement related to the component of TRM being analyzed. The TRM questionnaire was designed such that high mean scores per TRM component would mean higher levels of agreement to positive statements in the corresponding TRM component. The study was limited due to its small sample size and the use of a 4-point Likert scale instead of a 7-point scale.

Cronbach alpha was used to test the reliability of the item questions per component. A Cronbach's alpha coefficient greater than 0.90 meant that the component items have good internal consistency. (Table 1)

We used chi-square test to determine the association between various demographic variables such as type, age of the company, number of regular and non-regular employees, and business site with the existence of a TRM philosophy

Table 1. Cronbach alpha of TRM components

\begin{tabular}{lcc}
\multicolumn{1}{c}{ TRM } & Cronbach's Alpha & N of Items \\
Pay & 0.949 & 15 \\
Benefits & 0.953 & 15 \\
Work-life balance & 0.920 & 15 \\
Career development & 0.954 & 15 \\
Performance recognition & 0.957 & 15 \\
\hline
\end{tabular}


in a company. T-test was used to determine whether the differences in the mean scores per TRM component were statistically significant or not.

\section{RESULTS}

\section{Demographic Profile of Respondents}

There were a total of 74 respondents mainly in the human resource (HR) section representing the identified health-service industry. The majority of respondents had tenure between 1 to 5 years. This was closely followed by those with tenure between 5 to 10 years $(27 \%)$. Those with tenure of more than ten years but less than 15 years made up $12 \%$ of the respondents. The managerial level was the most represented (28\%), followed closely by the supervisory level (27\%) (Table 2).

More than three-fourths of the sample were employed in privately-owned companies. On the other hand, government agencies employed more than $10 \%$ of the sample. Almost half of the respondents' employer companies were in Metro Manila (46.0\%) followed by CALABARZON (Cavite, Laguna, Batangas, Rizal, Quezon) (21.6\%).

Only $32.4 \%$ or one-third of the companies had a labor union. Most had existed for more than 20 years. More than half of the companies had a decent employee size of 100 to 800 . In addition, more than half of the industries had less than 50 non-regular employees.

\section{TRM Philosophy in Selected Philippine Healthcare Companies}

More than two-fifths of the companies surveyed have a TRM philosophy. At the same time, 17 companies (23\%) do not have a TRM philosophy, $32 \%$ of the respondents do not know whether there is a TRM philosophy. Most companies with the philosophy introduce this during town halls. The next popular mode of information dissemination was during onboarding. (Figure 1)

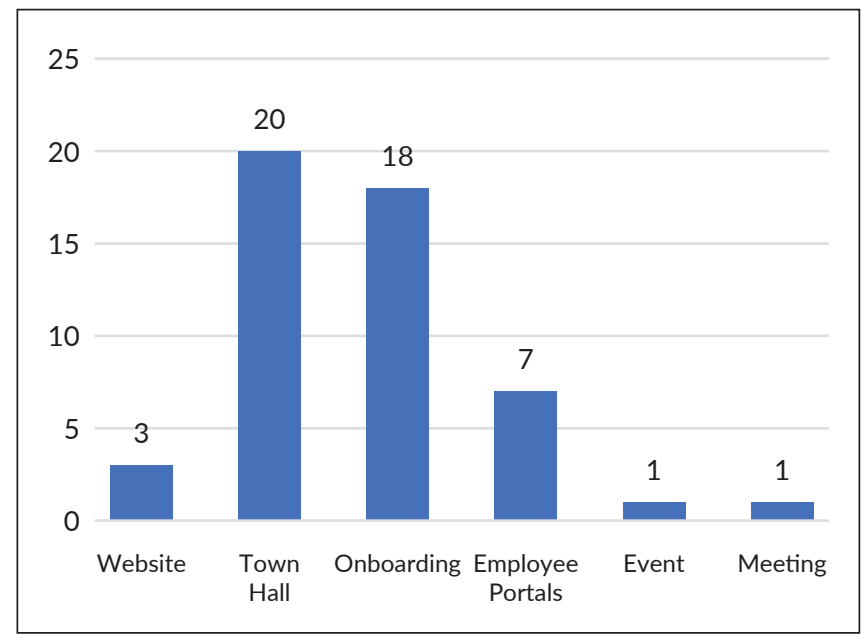

Figure 1. Frequency of mode of TRM information dissemination.

\section{TRM Philosophy in the Companies}

The survey on TRM philosophy was divided into five parts: pay, benefits, work-life balance, career development, and performance recognition. Each part was composed of 15 items, wherein each item tested the respondents' level

Table 2. Frequency distribution of respondents by company profile, employee profile, and TRM philosophy ( $\mathrm{N}=74)$

\begin{tabular}{|c|c|c|}
\hline Items & Frequency & Percentage (\%) \\
\hline \multicolumn{3}{|l|}{ Tenure (Years) } \\
\hline $1-5$ & 21 & 28.4 \\
\hline $6-10$ & 20 & 27.0 \\
\hline $11-15$ & 9 & 12.2 \\
\hline$<0.5$ & 6 & 8.1 \\
\hline $0.5-1$ & 6 & 8.1 \\
\hline $15-20$ & 6 & 8.1 \\
\hline$>25$ & 3 & 4.1 \\
\hline $20-25$ & 3 & 4.1 \\
\hline Total & 71 & 100.0 \\
\hline \multicolumn{3}{|l|}{ Rank } \\
\hline Managerial & 21 & 28.4 \\
\hline Supervisory & 20 & 27.0 \\
\hline Top management & 15 & 20.3 \\
\hline Rank and file & 12 & 16.2 \\
\hline Business owner & 3 & 4.1 \\
\hline \multicolumn{3}{|l|}{ Type of Company } \\
\hline Privately-owned & 57 & 77.0 \\
\hline Government & 9 & 12.2 \\
\hline Government-owned and controlled & 4 & 5.4 \\
\hline NGO & 2 & 2.7 \\
\hline Multinational & 1 & 1.4 \\
\hline \multicolumn{3}{|l|}{ Business Site of Companies } \\
\hline Metro Manila & 34 & 46.0 \\
\hline CALABARZON & 16 & 21.6 \\
\hline Luzon & 13 & 17.6 \\
\hline Mindanao & 7 & 9.5 \\
\hline Visayas & 4 & 5.4 \\
\hline \multicolumn{3}{|l|}{ Union } \\
\hline No & 48 & 64.9 \\
\hline Yes & 24 & 32.4 \\
\hline \multicolumn{3}{|l|}{ Years of Existence (Years) } \\
\hline$>20$ & 46 & 62.2 \\
\hline $5-20$ & 18 & 24.3 \\
\hline$<5$ & 9 & 12.2 \\
\hline \multicolumn{3}{|l|}{ No. of Employees } \\
\hline$>800$ & 12 & 16.2 \\
\hline $100-800$ & 41 & 55.4 \\
\hline$<100$ & 19 & 25.7 \\
\hline \multicolumn{3}{|l|}{ No. of Non-Regular Employees } \\
\hline$>250$ & 3 & 4.1 \\
\hline $50-250$ & 22 & 29.7 \\
\hline$<50$ & 39 & 52.7 \\
\hline \multicolumn{3}{|l|}{ TRM } \\
\hline Yes & 33 & 44.6 \\
\hline Not sure & 18 & 24.3 \\
\hline No & 17 & 23.0 \\
\hline
\end{tabular}


of agreement to a statement related to the component of TRM being analyzed. The TRM questionnaire was designed such that high mean scores per TRM component would mean higher levels of agreement to positive statements to the corresponding TRM component.

The pay item with the highest score among the healthcare companies was the existence of job evaluation and classification, while the item on receiving competitive pay and salary had the lowest score.

For the benefits phase, the highest mean item score was compliance with all the statutory benefits that the government prescribes. The lowest mean item score was the conduct of a benefits survey where the employees can choose their preferred benefits package. For the work-life balance phase, the highest mean item score was on a satisfactory work environment. The lowest mean item score was not experiencing burnout and stress.
For the career development phase, the highest item score was on the company's provision of experiences and opportunities to improve the current skill set of employees. On the other hand, the lowest item score was on facilitating career planning and career counseling program.

For the recognition phase, the highest mean item score was encouragement from superiors. Conversely, the lowest mean item score was on increased monetary compensation for accomplishments. (Table 3)

Figures 2 to 6 illustrate the percentage of item responses per TRM component to visualize the levels of agreement for the statements in the TRM questionnaire. As seen in the figures, almost all phases had higher proportions of agreement than disagreement except for two items. For example, under the work-life balance component, shows that the items "My company promotes flexi-time work arrangement for its employees" and "In my company,

Mechanism to address complaints about pay

Competent staff that handles compensation

Reviews pay system regularly

Easily hire talents because of competitive pay

Competitive pay structure

Variable pay programs

Job evaluation / Classification

Recommended job due to pay

Minimum wage based on labor standards

Competitive pay

Fairly and consistent pay policies

Pay policies are transparent

Fairly paid relative to job duties

Pay is enough for basic needs

Satisfied with pay
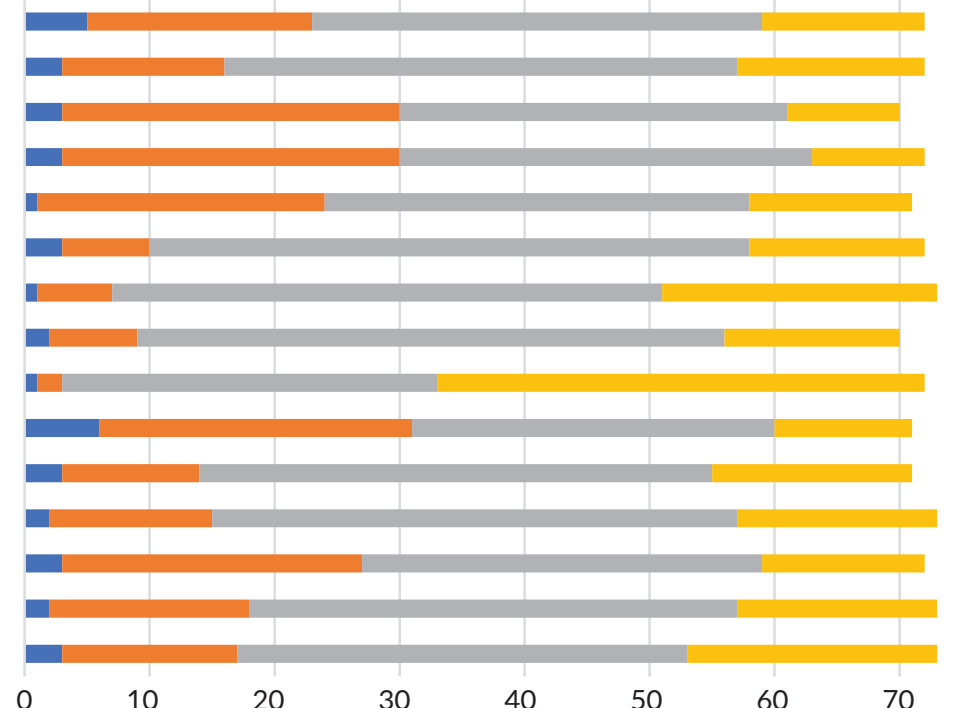

- Strongly Disagree $\square$ Disagree $\square$ Agree $\square$ Strongly Agree

Figure 2. Percentage of item responses in pay phase.

Table 3. Statements with the highest and lowest mean agreement scores per TRM component

\begin{tabular}{|c|c|c|c|c|}
\hline TRM Component & Statement with a highest mean item score & $\begin{array}{l}\text { Mean } \\
\text { Score }\end{array}$ & Statement with a lowest mean item score & $\begin{array}{l}\text { Mean } \\
\text { Score }\end{array}$ \\
\hline Pay & $\begin{array}{l}\text { My company observes the fundamental labor } \\
\text { standards relative to minimum wage fixing. }\end{array}$ & 3.49 & $\begin{array}{l}\text { My pay is competitive compared to what I could } \\
\text { have gotten in a similar position somewhere. }\end{array}$ & 2.62 \\
\hline Benefits & My company complies with all statutory benefits. & 3.32 & $\begin{array}{l}\text { My company allows employees to choose } \\
\text { benefits package. }\end{array}$ & 2.55 \\
\hline Work-life balance & My company is a fun environment to work in. & 3.11 & $\begin{array}{l}\text { In my company, the employees do not experience } \\
\text { burnout and stress. }\end{array}$ & 2.34 \\
\hline Career development & My company allows opportunities for job skillset. & 3.22 & My company has career counseling program. & 2.56 \\
\hline $\begin{array}{l}\text { Performance } \\
\text { recognition }\end{array}$ & My supervisor motivates excellent work. & 3.05 & $\begin{array}{l}\text { I am satisfied with monetary compensation for } \\
\text { my accomplishments. }\end{array}$ & 2.66 \\
\hline
\end{tabular}




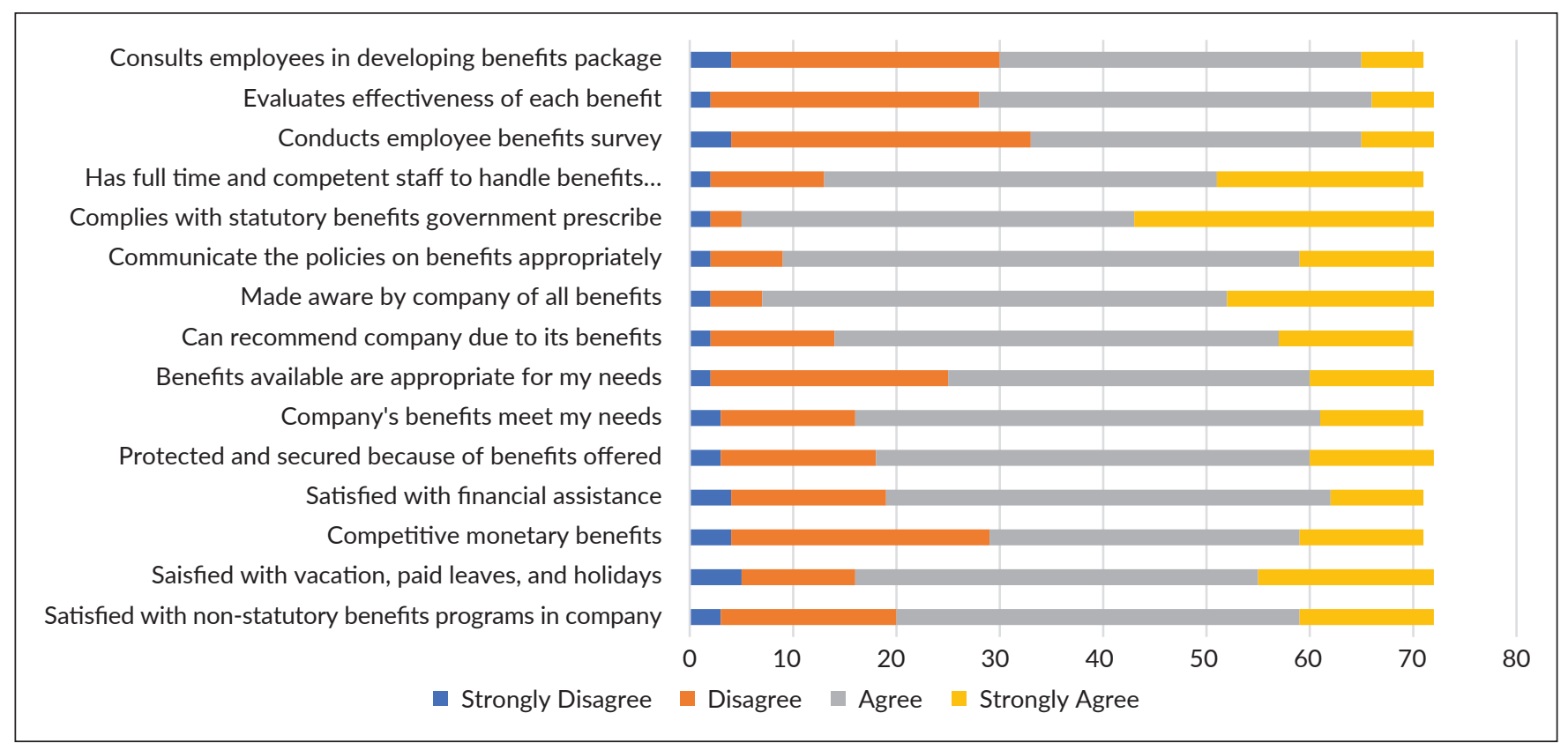

Figure 3. Percentage of item responses in benefits phase.

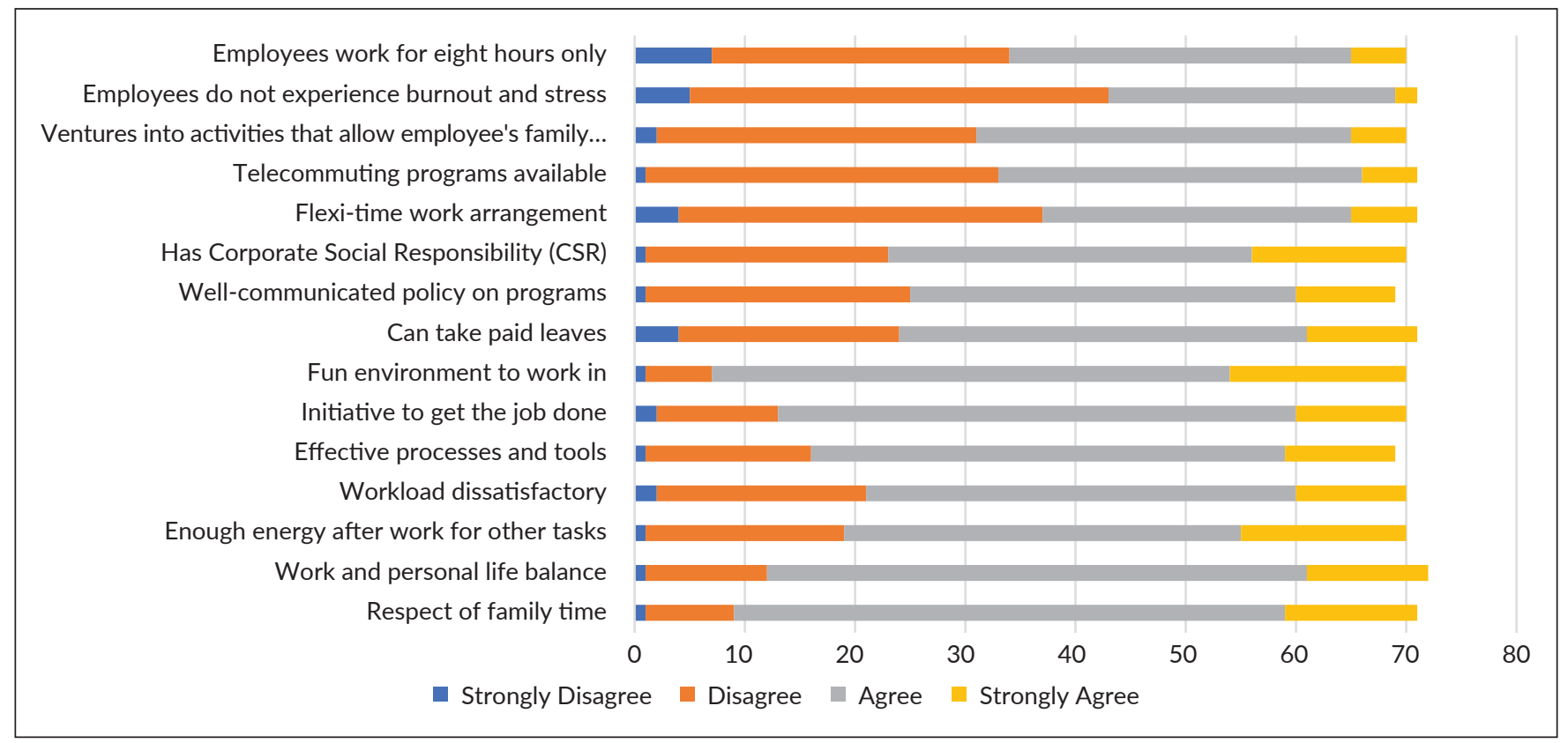

Figure 4. Percentage of item responses in work-life balance phase.

employees do not experience job burnout and stress." has a higher proportion of disagreement (Figure 4). Companies with and without TRM had little difference in work-life balance (Figure 3). The widest difference, on the other hand, was found in their pay.

The mean scores of those without TRM philosophy were not significantly lower than those without TRM philosophy across all factors (Table 4).

\section{Difference in Benefits Between Healthcare Com- panies With and Without TRM}

Results also show that except for the business site being in Manila, there were no other associations between the number of regular and non-regular employees, whether the company was privately-owned, and the age or number of years the company was in existence.

All variables had no association with TRM (Table 5). 
Table 4. T-test for Difference of Means by Existence of TRM

\begin{tabular}{lccc} 
& Mean Diff & $\mathbf{C l}$ & $\mathbf{p}$ \\
Pay & -0.05 & $(-0.36,0.27)$ & 0.776 \\
Benefits & -0.18 & $(-0.51,0.15)$ & 0.283 \\
Work-life balance & -0.07 & $(-0.33,0.18)$ & 0.575 \\
Career development & -0.05 & $(-0.32,0.21)$ & 0.679 \\
Performance recognition & -0.10 & $(-0.38,0.17)$ & 0.457 \\
\hline
\end{tabular}

Table 5. TRM with company profile

\begin{tabular}{lcc}
\multicolumn{1}{c}{ Company Profile } & Chi-square & P-value \\
\hline Company type & 0.683 & 0.409 \\
Years of existence & 2.220 & 0.330 \\
Number of employees & 3.967 & 0.138 \\
Number of non-regular employees & 4.166 & 0.125 \\
Business site & 5.516 & 0.019 \\
\hline
\end{tabular}

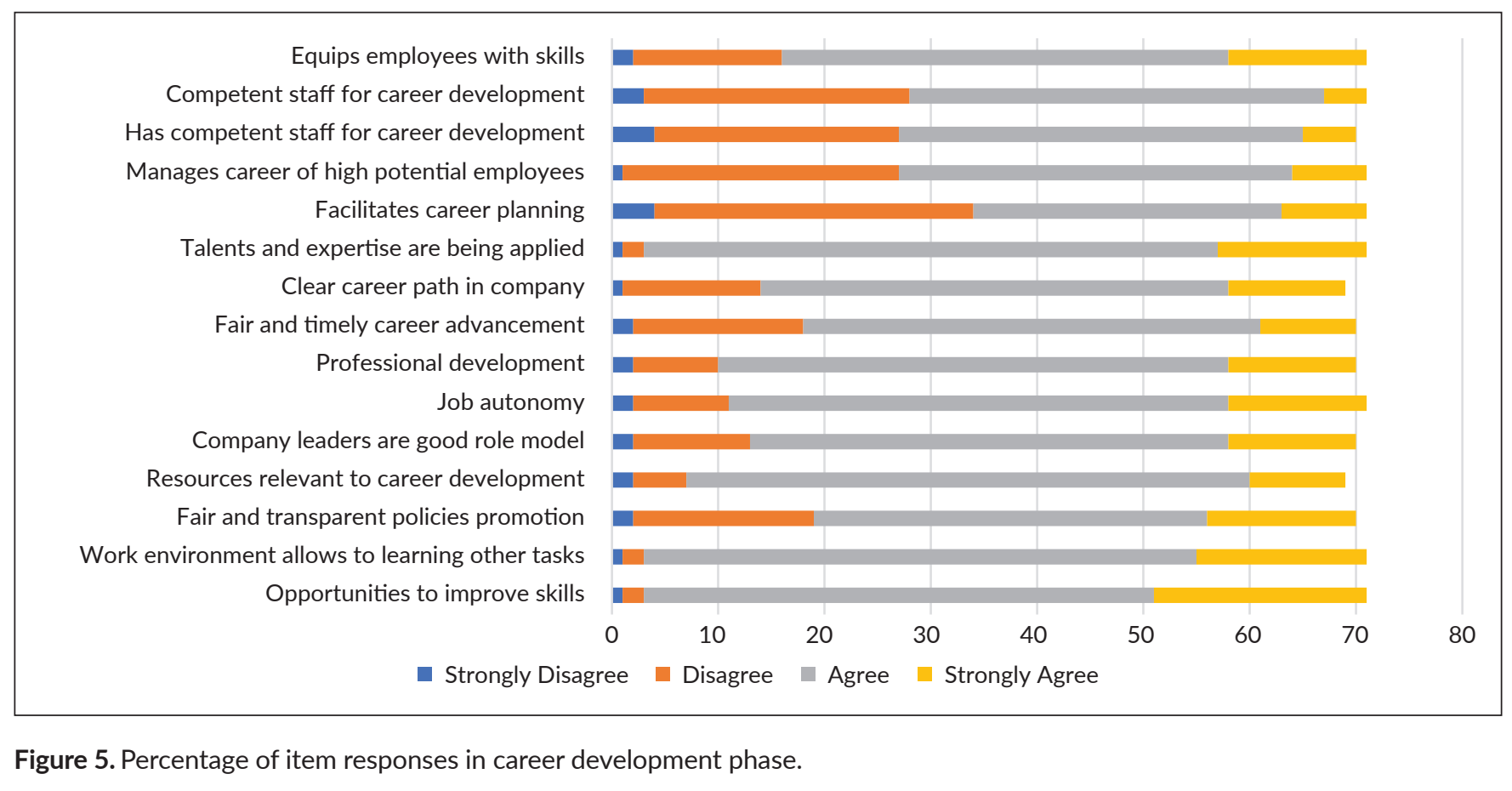

Figure 5. Percentage of item responses in career development phase.

Performance evaluation for career development Leadership initiatives

Competent staff that oversees performance

Performance management

Valid performance evaluation instrument Monetary compensation with accomplishment

Fair and timely rewards

Performance management is fair Superior recognized a good job Job motivation Job innovation Positive evaluation of efforts Feedback encouraged Job commitment Constructive feedback

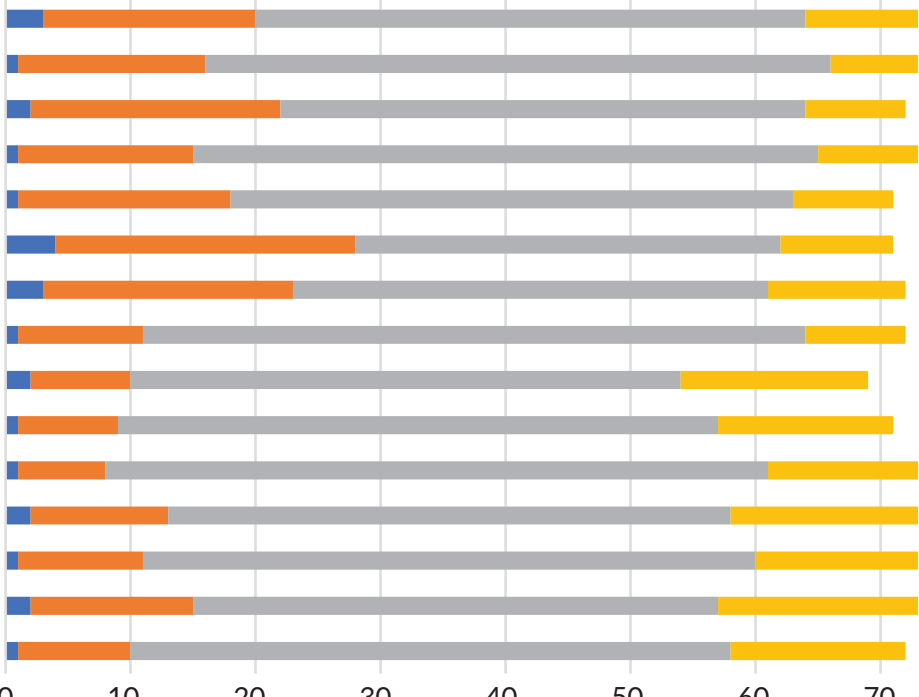
$\begin{array}{llllllll}0 & 10 & 20 & 30 & 40 & 50 & 60 & 70\end{array}$ Strongly Disagree $\square$ Disagree $\square$ Agree $\square$ Strongly Agree

Figure 6. Percentage of item responses in performance recognition phase. 


\section{DISCUSSION}

Among the healthcare companies that participated in the study ( $n=74)$, less than half (45\%) reported having total rewards philosophy. In a Total Rewards survey conducted by Deloitte Consulting in 2016, nearly 200 organizations shared their views on their total rewards philosophies and practices. Companies belonging to the health industry comprise $10 \%$ of the participants. Less than half of the companies under the life sciences and health care industry have total rewards. ${ }^{9}$ Hence, the level of integration of total rewards can be considered moderate at best. This level of integration coincides with the result of the survey.

Information about total rewards was more commonly distributed during town hall meetings and onboarding. Apart from town hall meetings and onboarding, other modes of communication for the total rewards philosophy include employee portals and websites. Despite the use of multiple channels, a large portion of participants, almost $24 \%$, were unsure whether they have total rewards in place in their companies. Employees had limited knowledge about total rewards, and companies were not communicating the philosophy well to their workers. Utilizing managers, personalizing information, and creating bite-sized chunks of content are some of the best ways to disseminate knowledge on total rewards in the healthcare industry. ${ }^{10}$ In general, it is important to take note of TRM in the Philippines as it was by James et al. (2015) that monetary and non-monetary rewards are instruments to aid the growth of an organization.

To gain insight into how the presence of a TRM philosophy in a company affects the pay, benefits, work-life balance, career development, and performance recognition of employees in the healthcare industry, the survey was divided into five parts. Each part was composed of 15 items, wherein each item tested the respondents' level of agreement to a statement related to the component of TRM being analyzed. The statements that garnered the highest mean agreement score regarding pay, benefits, work-life balance, career development, and recognition were considered strengths. In contrast, those with the lowest mean agreement scores were treated as gaps.

The total rewards policies concerning pay, job evaluation, and classifications in healthcare companies were determined as strengths. This advantage can be attributed to governing laws on occupational groups and salary grades, particularly Sections 6 and 9 of Republic Act (RA) No. 6758 or the Act Prescribing a Revised Compensation and Position Classification System in the government and for Other Purposes. According to the law, the Index of Occupational Services, Occupational Groups, Classes, and Salary Grades (IOS) was created. ${ }^{11}$ IOS defined the 'Medicine and Health Service' as the service including occupations concerned with medicine, surgery, dentistry, and optometry; and related patient care areas such as nursing, therapy, dietetics, rehabilitation, and pharmacy. It also includes occupations involving veterinary medicine, sanitation, and public health. Under the Medicine and Health Service, more than 180 occupations were listed along with their corresponding salary grade and class. ${ }^{12}$ Both public and private institutions use the IOS as a convenient guide in identifying classes appropriate to organizations' functions and assigning specific job descriptions, duties, and responsibilities for each occupation. However, developments in the context and nature of professions and their respective salary grades lead to the modification of the IOS by the Department of Budget and Management. ${ }^{13}$

The decentralized nature of the Philippine healthcare system accentuates the importance of the occupational groups and classes under the Medical and Health Service industry. Furthermore, as the system operates under three levels, namely national, regional, and LGU, the presence of distinct categories and determined salary grades within occupational groups effectively enhances the delivery of services to communities without compromising healthcare workers' compensation. ${ }^{14}$ On the downside, the lack of competitive pay was determined as a gap. This result is in line with the findings of an umbrella study on total rewards practices involving all industries in the Philippines. In the ILO Global Wage Database of 2015, the Philippines has ranked as one of the bottom ten countries with the least average nominal monthly wages in 31 selected countries in Asia and the Pacific. ${ }^{15}$ The compensation is meager in the healthcare industry. Salaries of workers in the medical and health service field pale in comparison to professionals in other sectors.

Additionally, there is a large gap between those working in private organizations and government institutions. ${ }^{16}$ The unequal distribution of the reservoir of human resources for health, coupled with the significant difference in wages between the urban and rural areas, causes the health workers to flock to metropolitan cities in search of more competitive pay while increasing the unemployment rate as a consequence. ${ }^{17}$ The limited job opportunities and the rise in the underemployment rate in the health industry lead to low wage growth. ${ }^{18}$ In general, incentives should be given to health care workers for better performance. In a paper, Abduljawad, and Al-Assaf $(2011)^{19}$ underscored the importance that those who have performed well should be rewarded financially. Overall, the general guidelines for these programs should be given through a sound system of performance measurement. Rewarding employees tend to motivate them to do more or better in their respective work. However, without any rewards for doing a job well done will warrant workers to lose interest in excelling and innovating, and this eventually leads to diminished morale and happiness in work. ${ }^{19}$

The strength determined in the benefits element of total rewards practices was the high compliance rate to statutory benefits that the government requires. This result is also in line with the umbrella study's findings on total rewards practices across all industries in the Philippines. Statutory 
benefits are given through mandatory contributions and insurances. The most common employee benefits indicated in the Philippines' Labor Law include leaves (i.e., sick, maternal, paternal, and parental), 13th-month pay, retirement, separation pay, and mandatory contributions to PhilHealth, SSS or GSIS, and Pag-IBIG. ${ }^{20}$

The high rate of compliance with the government's mandatory statutory benefits can be attributed to the initiatives of DOLE and ILO to establish a labor inspectorate system that will boost the compliance rate to general labor standards.$^{21}$ In the first quarter of 2017, launching the Labor Law Compliance Management Information System (LCSMIS) allowed for the quick labor inspection of more than ten thousand firms in the country. More were reported to have deficiencies and violations; the most common was non-remittance and coverage of funds for Pag-IBIG and SSS. ${ }^{22}$ The said firms were given a chance to remedy their deficiencies, leading to a high rate of compliance mirrored in the result.

The persistent gap for the benefits element was also the same as the one identified across all industries. Using a survey to allow employees to choose a benefit package that they would like to avail of is an unpopular practice in Philippine companies. As healthcare companies struggle in designing even the most basic of a one-size-fits-all benefits package, the personalization of benefits packages is considered a gap. The non-personalization of worker benefits or bundled benefits is a common practice in developing countries like the Philippines. Like how Filipino employers must pay workers' contributions to SSS, Pag-IBIG, and PhilHealth, developing countries also employ bundled social protection to follow international advice and standards organizations. ${ }^{23}$

Unlike highly industrialized countries, developing countries lack a well-developed tax base, have high administration costs, and have low labor productivity. These result in high payroll tax rates and low benefits with limited coverage. ${ }^{23}$ Thus, as an alternative, employers tend to rely on non-standard employment forms to substantiate noncompetitive wages and limited benefits coverage. Therefore, the prevalence of non-standard forms of employment is related to bundled worker benefits with limited coverage. Non-standard conditions of employment are particularly rampant in the country's healthcare industry. The Alliance of Health Workers cited extreme cases of long-term contractual work that lasted for almost 31 years. As the National Kidney Transplant Institute, some of the major hospitals in the country employ a third of their entire workers via a contractual labor scheme. ${ }^{24}$ This longstanding problem of contractualization in the country's health industry was cited in The Philippine Human Resources for Health Master Plan for 2005 to 2030. Temporary job orders and the contractualization of human resources for health were cited as both a weakness and a threat to the country's healthcare industry. ${ }^{16}$

Consequently, before implementing personalization initiatives for benefits packages, companies must first solve the underlying problem of non-competitive wages and improve the coverage of bundled worker benefits. Doing so will decrease informal employment, thereby strengthening the healthcare industry's labor market.

Based on the survey result, the greatest strength of the work-life balance aspect of total reward practices in Philippine organizations was fun or satisfactory work environment where employees can enjoy working with their teams. A team is defined as a group of people who operate their relationships within organizational bounds, are interdependent on their tasks while sharing responsibility for work outcomes. ${ }^{25}$ In a collectivist society where people are highly relational like the Philippines, ${ }^{26,27}$ teams tend to become more effective when members understand the value of maintaining dignified work relationships where sensitivity and reciprocity enhance a member's sense of self. ${ }^{28}$ This may be explained by collaboration in healthcare providers' safety culture in the Philippines. A study $(\mathrm{n}=335)$ concerning the public and private healthcare providers' perception of teamwork about safety determined that most health organizations in the Philippines pursue teamwork at a proactive level. ${ }^{29}$ Teamwork in healthcare reduces patient safety problems by improving the team members' morale, well-being, and cohesiveness. It also increases the team's viability or the degree to which a team will function over time. ${ }^{30,31}$

On the downside, healthcare workers in the Philippines suffer from burnout and work-related stress, as shown by this study's results. In the work-life balance aspect of total rewards in the Philippine health care industry, stress and burnout in workers are the greatest threat. Existing literature supports this result as well. For example, in a study assessing Filipino nurses' health and safety concerns, the highestranked problem was acute and chronic effects of stress and overwork. This finding is also in line with the result of a survey conducted by the American Nurses Association in $2001 .{ }^{32}$ Another study probing work-related stressors and stress levels among Filipino hospital nurses was conducted in 2017 ( $n=275)$. Using nine subscales to measure stress among participants, results revealed that Filipino nurses experience a moderate stress level. The workload is ranked as the highest source of stress. ${ }^{33}$ Filipino employees working in the healthcare industry are known for being too overworked. ${ }^{34,35}$ These studies support the result that healthcare workers' stress and burnout are significant weaknesses in the country's healthcare system. Moreover, most services in the healthcare setting are activities that should be done instantly, which contributes to stress. ${ }^{36}$

The study of Schwarts et al. (2019) ${ }^{37}$ found that it is common for healthcare workers to experience problems concerning work-life balance, and this has the strongest association with personal burnout. The study also found that a higher work-life balance score was associated with better teamwork and patient safety norms, better leadership, and increased readiness for quality improvement, and lower burnout in oneself and one's colleague. ${ }^{37}$ 


\section{Career Development}

According to the survey result for the career development aspect of total rewards in the Philippine healthcare industry, the provision of experiences and training opportunities to health workers can be considered a strength.

With many Filipino's seeking to find employment abroad, ${ }^{38}$ coupled with the government's policy on labor migration, ${ }^{39}$ the abundance of training opportunities tailored for health workers is not surprising. Technical Education and Skills Development Authority (TESDA), the leading body that aims to make technical education more accessible to Filipinos, has several developed training curricula for health workers seeking certifications. ${ }^{40}$ Furthermore, the courses offered by TESDA are significantly cheaper, hence, healthcare companies find it easy to provide training opportunities to their employees.

The abundance of work experiences, on the other hand, may have stemmed from the volunteering phenomenon that is rampant in the country's health industry. Before being given job orders or even contractual work, health workers tend to sacrifice paid work and volunteer at hospitals to gain work experience. The volunteers work 12-hour shifts four to five times a week while being given a monthly compensation as low as Php $1,000 .^{35}$ This phenomenon was worse when there was a shortage of nurses and health workers in developed countries from 2000 to $2010 .^{41}$

According to the survey result in this study, healthcare workers were provided with ample training and work experiences; and this can be considered one of the many strengths of the country's human resource for health (HRH). There are many underlying reasons for this, but the most notable would-be health workers' desire to find more lucrative opportunities abroad. To migrate, they must gather a significant amount of work experience and undergo many training courses. ${ }^{42}$ Career development also plays a role in the increased productivity of employees along with recognition. James et. al $(2015)^{43}$ found that there is a positive relationship between non-monetary rewards (i.e., career development and recognition) and employees' productivity. This is due to the increased boost of self-confidence for the worker contribution therefore the organization is using a rewards system as an incentive for employees to maximize work productivity and quality. ${ }^{43}$

On the downside, there are inadequate opportunities for career advancement in the country's health care industry. Additionally, career counseling is also seldom practiced in our HRH. This weakness is cited in several studies. For example, doctors lack opportunities to pursue specialization while nurses fail to advance in their profession due to a lack of available positions in public and private hospitals. ${ }^{5}$ The narrow paths for career advancement are also a commonly cited reason for wanting to work abroad.

Policy-wise, provisions for the establishment of career paths and counseling programs exist in the Magna Carta of Public Health Workers. In Section 2 of its Implementing
Rules and Regulations, a Human Resource Development Plan must include establishing career paths or plans for every category of public health worker to serve as one of the bases for reclassifying jobs or upgrading of positions. Additionally, it must include establishing alternative approaches for improving job performance such as coaching, counseling, job rotation, on-the-job training, and others. ${ }^{44}$ To deter them from working and migrating abroad, the government must first successfully implement the Magna Carta for Public Health Worker's provisions for the Human Resource Development Plan, specifically those for health workers' career advancement.

The Filipino workplace is known to be full of hospitality and camaraderie. ${ }^{45}$ This point coincides with the survey result on the Recognition aspect of total rewards practices in the Philippines' healthcare industry. Based on the survey, employees often received encouragement from their supervisors to exceed expectations; this is considered a significant strength in healthcare companies. This result also coincided with the umbrella study's impact on Total Reward practices across all industries in the Philippines.

A systematic review of 20 studies, which aimed to examine the importance of different motivation factors and the effectiveness of interventions to improve health workers' motivation in developing countries, found that recognition or appreciation from managers, colleagues, and the community is crucial for inspiration. It was a recurring theme among the studies examined, where $70 \%$ of the chosen studies cited it as one of the most important motivating factors for health workers. ${ }^{46}$ This study emphasizes the role recognition has to play in the work experiences of health workers. Managers in the country's health industry may have been fully aware of the importance of encouragement and recognition to their subordinates. When coupled with the friendly nature of workers in the same workplace, this awareness may have been why managers and immediate supervisors actively give out encouragement to the health workers in their companies.

Public and private health institutions may have different ways of rewarding their employees. Still, for public hospitals, the Magna Carta for Public Health Workers states that incentive award systems must be established by the Secretary of Health and other concerned government agencies. ${ }^{44}$ However, specific guidelines on establishing said incentive systems were not included in the implementing rules and regulations. This vagueness from the legislative side enabled companies to overlook monetary compensations due to accomplished health workers.

Due to the limited sample size, the results of correlation tests between the demographic variables and the existence of a Total Rewards philosophy in a company were inconclusive. Hence, increasing the number of participants is included in this study's recommendations.

Statistical analysis of the computed mean scores per examined aspect of total rewards revealed no significant difference between companies with and without an established total rewards philosophy regarding pay, benefits, work-life 
balance, career development, and recognition. This result is contrary to the findings of Mabaso and Dlamini (2018) ${ }^{47}$ where they found a positive and significant correlation between elements of total rewards and organizational commitment. This means that performance management, career opportunities, compensation, benefits, and work-life balance significantly predicted organizational commitment. ${ }^{47}$ The same study mentioned that perception of fair rewards and justice leads to higher levels of satisfaction and long-term commitment in an organization. ${ }^{47}$

In this study in the Philippines, although there is a moderate level of integration of total rewards philosophy in the country's healthcare industry, the practices can be deemed ineffective given that the differences between companies with and without total rewards were not significant as per the study results.

Total Rewards combines both monetary and nonmonetary rewards used by organizations to generate valuable business results. However, the severe, deep-rooted problems of the country's human resources for health eclipse financial and non-monetary rewards given to health workers. For example, although the Department of Health allocates a massive percentage of its budget on personnel services and salaries for human resources, ${ }^{48}$ attempts to improve direct wages and social security benefits still have challenges.

Some total rewards practices are even impossible to implement under the current health system. A helpful example would be the relationship between work-life balance and staff shortage. Efforts to improve the employees' worklife balance are challenging under the perennial lack of skilled staff due to labor migration policies. As a result, employees need to work long hours to make up for the limited workforce. Consequently, health workers usually suffer from burnout and extreme stress, as per the results of this study.

The implementation of total rewards policies is more commonly viewed from a strategic point of view. It requires buy-in from owners and members of the top management. In other words, on top of the country's labor laws and standards, it is an additional effort undertaken to attract and retain talent. Therefore, if the basic standards stated in the labor laws are not adequately implemented, total rewards practices can be deemed insignificant.

\section{CONCLUSION}

Healthcare companies, particularly those operating in Metro Manila, are likely to have an established TRM philosophy.

Only $44 \%$ of respondents were employed by healthcare companies with a TRM philosophy. However, healthcare companies that do practice TRM had ineffective systems and policies in place. Employees who worked in companies with TRM did not necessarily experience better pay, benefits, career development, and performance recognition than those are working without TRM. This may be due to ineffective integration of TRM in the company's organizational practice, or that improvement may not have been sufficient to warrant a change towards better pay and other socio-economic benefits for the employees.

These findings of this study suggest that even companies with an established TRM philosophy need significant improvement in their TRM processes for TRM to translate to better pay, benefits, work-life balance, career development, and performance recognition.

\section{Statement of Authorship}

All authors contributed in the conceptualization of work, acquisition and analysis of data, drafting and revising, and approved the final version to be published.

\section{Author Disclosure}

All authors declared no conflicts of interest.

\section{Funding Source}

The study was implemented through the School of Labor and Industrial Relations (SOLAIR), University of the Philippines Diliman.

\section{REFERENCES}

1. Ghebreyesus T. Health is a fundamental human right [Internet]. Geneva: World Health Organization; c2020 updated 2017 Dec 10. [cited 2020 Jun 2]. Available from: https://www.who.int/mediacentre/news/ statements/fundamental-human-right/en/.

2. Castro Lopes S, Guerra-Arias M, Buchan J, Pozo-Martin F, Nove A. A rapid review of the rate of attrition from the health workforce. Hum Resour Health. 2017 Mar 1; 15(1):21.

3. Cometto G, Tulenko K, Muula AS, Krech R. Health workforce brain drain: from denouncing the challenge to solving the problem. PLoS Med. 2013; 10(9):e1001514. PubMed PMID: 24068895.

4. Brush BL, Sochalski J. International nurse migration: lessons from the Philippines. Policy Polit Nurs Pract. 2007 Feb; 8(1):37-46.

5. Castro-Palaganas E, Spitzer DL, Kabamalan MM, Sanchez MC, Caricativo R, Runnels V, et al. An examination of the causes, consequences, and policy responses to the migration of highly trained health personnel from the Philippines: the high cost of living/leaving-a mixed method study. Hum Resour Health. 2017 Mar 31; 15(1):25.

6. International Labour Office. Migration of health workers: country case study Philippines. Geneva: ILO Publications Bureau [Internet]. 2005. [cited 2020 Jun 2]. Available from: https:/www.ilo.org/wcmsp5/groups/ public/---ed_dialogue/---sector/documents/publication/wcms_161163. pdf.

7. Philippine Statistics Authority. Labor Turnover Survey, 4th Quarter of 2018 [Internet]. 2019 Apr 30 [cited 2020 Jun 2]. Available from: https://psa.gov.ph/sites/default/files/PR_4Q2018LTS_signed.pdf.

8. WorldatWork. The WorldatWork handbook of compensation, benefits, and total rewards: a comprehensive guide for HR professionals. Canada: John Wiley \& Sons; 2007.

9. Deloitte Consulting LLP. Total Rewards Survey: Initial Findings [Internet]. 2017 [cited 2020 Jun 26]. Available from: https://www2. deloitte.com/content/dam/Deloitte/us/Documents/human-capital/ us-cons-total-rewards-survey-initial-findings.pdf.

10. Tyukodi M. Effectively communicating total rewards in health care [Internet]. Chicago (IL): ASC Communications; c2020 [updated 2016 Sep 26; cited 2020 Jun 26]. Available from: https://www. beckershospitalreview.com/hr/effectively-communicating-total-rewardsin-health-care.html.

11. Compensation and Position Classification Act of 1989. R. A. No. 6758 (Aug. 21, 1989). 
12. Department of Budget and Management.INDEX of OCCUPATIONAL SERVICES, OCCUPATIONAL GROUPS, CLASSES, and SALARY GRADES [Internet]. 2018 Oct [cited 2020 Jun 12]. Available from: https://www.dbm.gov.ph/wp-content/uploads/OPCCB/BC/BC-20184-vol-i.pdf.

13. Diokno BE. Foreword. In: Index of occupational services, occupational groups, classes, and salary grades [Internet]. 2018 Oct [cited 2020 Jun 12]. Available from: https://www.dbm.gov.ph/wp-content/uploads/ OPCCB/BC/BC-2018-4-vol-i.pdf.

14. Devlin K, Farnham-Egan K, Pandit-Rajani T. Community health systems catalog country profile: Philippines [Internet]. Arlington: Advancing Partners \& Communities; 2016 [cited 2020 Jun 12]. Available from: https://www.advancingpartners.org/sites/default/files/catalog/profiles/ apc_philippines_chs_catalog_profile_0.pdf

15. International Labor Organization. Wages in Asia and the Pacific and the Arab States [Internet]. 2016 [cited 2020 May 29]. Available from: https://www.ilo.org/wcmsp5/groups/public/---asia/---ro-bangkok/ documents/publication/wcms_534369.pdf.

16. Lorenzo M. The Philippine Human Resource for Health Master Plan (2005 - 2030) [Internet]. 2008 Mar 5 [cited 2020 Jun 12]. Available from: https://www.who.int/workforcealliance/forum/presentations/ Fely_Marilyn_Elegado.pdf.

17. Department of Health. The Philippine health system at a glance [Internet]. 2009 [cited 2020 Jun 12]. Available from: https://www.doh. gov.ph/sites/default/files/basic-page/chapter-one.pdf.

18. Jericho G. Looking for the cause of low wage growth? It's underemployment [Internet]. London (UK): Guardian News \& Media Limited; c2020 [updated 2017 Jun 19; cited 2020 Jun 12]. Available from: https://www.theguardian.com/business/grogonomics/2017/ jun/19/higher-wages-would-be-nice-mr-lowe-but-weak-unions-makeit-unlikely.

19. Abduljawad A, Al-Assaf AF. Incentives for better performance in health care. Sultan Qaboos Univ Med J. 2011 May;11(2):201-6.

20. Bureau of Working Conditions, Department of Labor and Employment. HANDBOOK OF WORKERS' STATUTORY MONETARY BENEFITS 2019 Edition. [Internet]. Manila City: Bureau of Working Conditions (BWC), Department of Labor and Employment (DOLE); 2019 [cited 2020 May 29]. Available from: http://www.ble.dole.gov. ph/downloads/2019-Edition-of-Handbook-on-Workers-StatutoryMonetary-Benefits.pdf.

21. International Labour Organization [Internet]. Geneva: International Labour Organization (ILO); c1996-2021 [cited 2020 May 29]. Building the Capacity of the Philippines Labour Inspectorate; [about 2 screens]. Available from: https://www.ilo.org/manila/projects/WCMS_379086/ lang--en/index.htm.

22. Medenilla S. Over 5,000 firms nationwide violated labor laws - DOLE [Internet]. Manila: Manila Bulletin; c2020 [updated 2017; cited 2020 May 28]. Available from: https://news.mb.com.ph/2017/06/25/over5000-firms-nationwide-violated-labor-laws-dole/.

23. Fox L. Why are worker benefits and protections so limited in developing countries? [Internet]. 2016 [cited 2020 Jun 13]. Available from: https://www.brookings.edu/wp-content/uploads/2016/07/Global_ 20160720_Blum_FoxWeb.pdf

24. Ellao J. Contractualization, poor pay continues to hound health workers [Internet]. Manila: Bulatlat.com; c2016 [updated 2019 May 7; cited 2020 Jun 13]. Available from: https://www.bulatlat.com/2019/05/07/ contractualization-poor-pay-continue-to-hound-health-workers/

25. Cohen SG, Bailey DE. What makes teams work: group effectiveness research from the shop floor to the executive suite. J Manage. 1997; 23(3):239-90.

26. Jocano FL. Towards developing a Filipino corporate culture. Quezon City: Punlad Research House; 1988.

27. Hofstede G. National cultures in four dimensions: a research-based theory of cultural differences among nations. Int Studies of Man \& Org. 1983:8(1-2):46-74.

28. Alafriz C, Hechanova M, Teng-Calleja M, Pesigan IJA. A Model for Filipino Work Team Effectiveness. Philippine Journal of Psychology. 2014 Dec; 47(2):99-124.

29. Jabonete F, Concepcion L. Perceived safety culture of healthcare providers in hospitals in the Philippines. J Sci Technol Arts Res. 2016 Aug; 2(1):1-14.
30. Cannon-Bowers JA, Salas E. Teamwork Competencies: The Interaction of team member knowledge, skills, and attitudes. In: O’Neil HF, editor. Workforce Readiness Competencies and Assessment. New Jersey: Lawrence Erlbaum Associates; 1997. p. 151-74.

31. El-Jardali F, Jaafar M, Dimassi H, Jamal D, Hamdan R. The current state of patient safety culture in Lebanese hospitals: a study at baseline. Int J Qual Health Care. 2010 Oct; 22(5):386-95.

32. de Castro AB, Cabrera SL, Gee GC, Fujishiro K, Tagalog EA. Occupational health and safety issues among nurses in the Philippines. AAOHN J. 2009 Apr; 57(4):149-57.

33. Jabonete F, Dayrit A. Reported work-related stressors among staff nurses in Metro Manila, Philippines. J Sci Technol Arts Res J. 2017 Sep;3:69-85.

34. Yee J. The Philippines amidst the 'healthcare crisis' [Internet]. Makati City: INQUIRER.net; c1997-2020 [updated 2019 Oct 19; cited 2020 Jun 21]. Available from: https://newsinfo.inquirer.net/1179316/ph-inmidst-of-health-care-crisis.

35. Ladrido P. The burden of being a public health worker in the Philippines [Internet]. Mandaluyong City: Nine Media Corp; c2015 [updated 2019 Apr 22; cited 2020 Jun 21]. Available from: https://cnnphilippines.com/ life/culture/2019/4/22/government-health-workers-Philippines.html.

36. Shivakumar K, Pujar V. Work life balance in the health care sector. Amity J Healthcare Manag. 2016;1(2):45-54.

37. Schwarts S, Adair K, Bae J, Rehder K, Shanafel T, Profit J, et al. Work-life balance behavior cluster in work settings and relate to burnout and safety culture: a cross-sectional survey analysis. BMJ Qual Saf. 2019; 28:142-50

38. IBON Foundation Inc. Economy under the Aquino administration: a case of worsening exclusivity [Internet]. Quezon City: IBON Foundation Inc.; c2020 [updated 2014 Aug 18; cited 2020 Jun 25]. Available from: https://defence.pk/pdf/threads/philippines-defence-forum.234998/ page- 46.

39. O'Neil K. Labor export as government policy: the case of the Philippines [Internet]. Washington: Migration Policy Institute; c2001-2020; [updated 2004 Jan 1; cited 2020 Jun 25]. Available from: https://www. migrationpolicy.org/article/labor-export-government-policy-casephilippines.

40. TESDA [Internet]. Manila City: Tesda Courses; c2015 [cited 2020 Jun 25]. List of TESDA short courses offered by training centers; [about 3 screens]. Available from: http://tesdatrainingcourses.com/list-oftesda-short-courses-offered-in-training-centers.html.

41. Pring C, Roco I. The Volunteer Phenomenon of Nurses in the Philippines. Asian J Health Sci. 2012 Jan;2(1):95-110.

42. Local Government Employees. Total reward - how to get started [Internet]. 2017 [cited Aug 2021]. Available from https://www.local. gov.uk/sites/default/files/documents/total-reward-9b8.pdf.

43. James O, Ella R, Nkamare S, Lukpata F, Uwa S, Mbum P. Effects of reward system among health care workers performance: a case study of university of Calabar, Nigeria. J Hosp Adm. 2015 Apr;4(3):45-53.

44. Revised Implementing Rules and Regulations on the Magna Carta of Public Health Workers or R.A. 7305 [Internet]. Available from: https://www.chanrobles.com/REVISED\%20IMPLEMENTING\%20 RULES\%20AND\%20REGULATIONS\%20ON\%20THE\%20 MAGNA\%20CARTA\%20OF\%20PUBLIC\%20HEALTH\%20 WORKERS\%20OR\%20R.A.\%207305.pdf.

45. Saa UM. Pakikisama [Internet]. Quezon City: Delegation of The Philippines; c2019 [updated 2013 Nov 22; cited 2020 Jun 25]. Available from: https://philippines.xaverians.org/theologate/3-theologasiaph-p-2828

46. Willis-Shattuck M, Bidwell P, Thomas S, Wyness L, Blaauw D, Ditlopo P. Motivation and retention of health workers in developing countries: a systematic review. BMC Health Serv Res. 2008 Dec 4; 8:247.

47. Mabaso C, Dlamini B. Total rewards and its effects on organizational commitment in higher education institutions. SA J Hum Resour Manag. 2018 May; 16(1):a913

48. World Health Organization. The Philippines' Health System Review. Vol. 8 No. 2 [Internet]. New Delhi: World Health Organization, Regional Office for South-East Asia; 2018 [cited 2020 Jun 25]. Available from: https://apps.who.int/iris/bitstream/handle/10665/ 274579/9789290226734-eng.pdf?sequence=1\&isAllowed=y. 